\title{
Pathophysiology of cardiovascular disease in rare anemias
}

\author{
Athanasios Aessopos, Dimitrios Farmakis \\ University of Athens Medical School, Athens, Greece
}

Rare anemias encompass a large and markedly heterogeneous group of nearly 90 different conditions, mostly congenital or genetically determined, that, according to the definition of the European Commission, have a global prevalence of less than 5 per 10,000 individuals. However, the geographical distribution of several of those anemias varies considerably and thus their local prevalence may be significantly higher in certain regions.

Due to their extremely low prevalence, many of the rare anemias are poorly understood. owever, these conditions share some basic features, such as anemia, hemolysis and red blood cell defects that contribute significantly to the development of cardiovascular complications. Thus, our hitherto knowledge of the pathophysiology of cardiovascular disease in those conditions is mainly based on the ones with a considerable local prevalence that has allowed their adequate study. Among them, the hemoglobinopathies, including mainly the thalassemias, particularly beta-thalassemia, and the sickle cell disease (SCD), are the most comprehensively addressed.

Heart disease is the outcome of three main factors, the anemia itself with its consequences, the particular features and mechanisms related to the underlying molecular defect and the applied therapy.

Chronic anemia causes tissue hypoxia, which in turn motivates a number of compensatory reactions, including high output state that may lead to heart failure when anemia is prolonged and severe. Actually, high output heart failure was the main cause of death in patients with thalassemia major, the most severe clinical form of betathalassemia, before regular blood transfusion therapy was established in late 1960s. High output state still contributes to complications such as left ventricular dysfunction, valvular heart disease and pulmonary hypertension, when considerable chronic anemia remains untreated, as in the case of traditionally managed patients with thalassemia intermedia.

Chronic hemolysis is frequently involved in rare anemias and leads to nitric oxide deficiency, which in turns causes endothelial dysfunction with impaired vascular tone, vascular inflammation and hypercoagulability. These abnormalities affect adversely the function

Correspondence: Athanasios Aessopos

(C) Copyright A. Aessopos and D. Farmakis, 2013

Licensee PAGEPress, Italy

Thalassemia Reports 2013; 3(s1):e7

doi:10.4081/thal.2013.s1.e7

This article is distributed under the terms of the Creative Commons Attribution Noncommercial License (by-nc 3.0) which permits any noncommercial use, distribution, and reproduction in any medium, provided the original author(s) and source are credited.

Parts of this work were presented at the

" 3 rd Pan-European Conference on Haemoglobinopathies and Rare Anaemias", Limassol (Cyprus), 24-26 October 2012. of the cardiovascular system and contribute to the development of complications such as pulmonary hypertension and thromboembolic events. In addition, the free heme and its byproducts released during hemolysis bear oxidative properties that may cause myocardial and other tissue damage.

On the other hand, the erythrocyte itself is not normal in several of those anemias. The typical example is the SCD, in which the synthesis of the abnormal hemoglobin $\mathrm{S}$ causes deformation of erythrocytes under certain conditions that in turn changes their rheological properties and its interaction with endothelium. These latter affect the microvascular circulation and cause episodes of microvascular obstruction with subsequent organ damage. In this context, myocardial ischemia has been documented in SCD patients without stenotic coronary artery lesions. Moreover, erythrocytes in beta-thalassemias bear a precoagulant surface, which also contributes to a hypercoagulable state and thus to thromboembolic complications.

Coexisting defects may also contribute to the pathophysiology of heart disease. An acquired defect of the elastic tissue, similar to the one of hereditary pseudoxanthoma elasticum (PXE) has been observed with a considerably high, age-related frequency in patients with hemoglobinopathies and other rare anemias with different genetical background and is probably related to hemolysis. This PXElike condition, among other complications, causes endocardial and arterial calcification that may cause valvular abnormalities such aortic stenosis and increased arterial stiffness, respectively. Moreover, PXE is also related to an increased bleeding tendency and intracranial hemorrhages have been documented in beta-thalassemia patients with PXE-like stigmata.

The third component affecting crucially the pathophysiology of heart disease is the applied therapy. Blood transfusion therapy constitutes the cornerstone for the treatment of chronic severe anemia; they alleviate the effects of anemia on the cardiovascular and other systems, hence modifying the natural history of the disease. However, repetitive blood transfusions lead to iron overload that causes tissue damage through oxidative stress. The heart is among the organs that are prone to iron overload and the resulting cardiac dysfunction is caused both directly due to myocardial iron deposition and indirectly due to ironrelated complications from other organs or systems, including liver disease, endocrine system abnormalities and increased susceptibility to infections. Iron overload cardiomyopathy is characterized by ventricular diastolic and/or systolic dysfunction and finally heart failure and was the main cause of death in regularly transfused thalassemia major patients before the introduction of iron chelation therapy in early 1970 s. Iron chelation therapy prevents the development of iron overload-related complications such as heart failure, and may also improve considerably cardiac function in patients already with iron overload cardiomyopathy.

Anemia along with iron overload and blood borne infections resulting from the applied transfusion therapy, as well as some coexistent immune defects lead to an increased susceptibility to infections that among other infections may result in pericarditis and/or myocarditis.(1-11) 


\section{References}

1. Engle MA, Erlandson M, Smith CH. Late cardiac complications of chronic, refractory anemia with hemochromatosis. Circulation 1964; 30:698-705.

2. Kremastinos DT, Tiniakos G, Theodorakis GN, Katritsis DG, Toutouzas PK. Myocarditis in $\beta$-Thalassemia Major: A Cause of Heart Failure. Circulation 1995; 91:66-71.

3. Aessopos A, Farmakis D, Karagiorga M, et al. Cardiac Involvement in Thalassemia Intermedia: A Multicenter Study. Blood 2001; 97:3411-6.

4. Aessopos A, Tsironi M, Vassiliadis I, et al. Exercise-induced myocardial perfusion abnormalities in sickle beta-thalassemia: Tc99m tetrofosmin gated SPECT imaging study. Am J Med 2001; 111:355-60.

5. Aessopos A, Farmakis D, Loukopoulos D. Elastic tissue abnormali- ties resembling pseudoxanthoma elasticum in beta thalassemia and the sickling syndromes. Blood 2002; 99:30-5.

6. Farmakis D, Giakoumis A, Polymeropoulos E, Aessopos A. Pathogenetic aspects of immune deficiency associated with betathalassemia. Med Sci Monit 2003; 9:RA19-22.

7. Aessopos A, Farmakis D, Deftereos S, et al. Thalassemia heart disease: a comparative evaluation of thalassemia major and thalassemia intermedia. Chest 2005; 127:1523-30.

8. Aessopos A, Kati M, Farmakis D. Heart disease in thalassemia intermedia: a review of the underlying pathophysiology. Haematologica 2007; 92:658-65.

9. Aessopos A, Farmakis D, Trompoukis C, et al. Cardiac involvement in sickle beta-thalassemia. Ann Hematol 2009; 88:557-64.

10. Kremastinos DT, Farmakis D. Iron overload cardiomyopathy in clinical practice. Circulation 2011; 124:2253-63.

11. Farmakis D, Aessopos A. Pulmonary hypertension associated with hemoglobinopathies: Prevalent but overlooked. Circulation 2011; 123:1227-32.

\section{Oral presentation}

Oral presentation is available online 